\title{
Desafios postos aos Programas de Pós-graduação em Serviço Social no contexto de desmonte do ensino superior
}

Challenges to the Graduate Programs in Social Work in the context of dismantling higher education

Mariangela Belfiore Wanderley ${ }^{a}$

(D) http://orcid.org/0000-0003-3894-6478

Maria Liduína de Oliveira e Silva

(D) http://orcid.org/0000-0002-7904-4836

Raquel Santos Sant'Anac

(1) https://orcid.org/0000-0002-2270-554

Rosangela Dias O. da Paz

(D) http://orcid.org/0000-0003-3547-1286

ste número da Revista Serviço Social \& Sociedade tem como tema a Inserção Social da Pós-Graduação em Serviço Social e cumpre um importante papel no sentido de dar visibilidade e fortalecer a área da pós-graduação em serviço social.

Este número vem a público num momento cuja realidade mundial e, em específico do Brasil, é de extrema gravidade. Assolados pela pandemia provocada pelo vírus Sars 2, ou o novo coronavírus, como ficou conhecido, causador da Covid-19, o mundo está acompanhando desde janeiro de 2020 as mortes de mais de 500 mil pessoas e mais de $10 \mathrm{mi}$ lhões de infectados; sendo que os países que lideram as estatísticas de mortes são Estados Unidos e Brasil. No final de junho de 2020, o Brasil 
tem cerca de 1 milhão e meio de infectados segundo os números oficiais e já contabiliza mais de 60 mil mortes (Nogueira, 2020). Entretanto, se levarmos em consideração a subnotificação da doença e quase ausência de testes, chegaremos a números ainda mais estarrecedores.

A Covid-19 é uma doença grave altamente transmissível e que segue sem tratamento e sem vacina. Grande parte dos infectados permanecem assintomáticos, aqueles mais vulneráveis em função da idade ou das condições sociais ou de saúde estão sob os maiores riscos. A única possibilidade de controle da doença segue sendo o isolamento social, que nas condições vivenciadas pela maioria da população brasileira é impossível de se efetivar devido às condições econômicas e/ou de moradia precária. Novamente, os mais pobres vivenciam de maneira mais dramática esta situação: no Brasil a maioria dos casos de óbito são de pessoas negras e pobres, ou seja, aquelas que têm menos condições de se proteger e de receber assistência médica (Amparo, 2020).

Esta grave crise sanitária está ocorrendo no País cujo governo federal mantém uma posição negacionista que minimiza as consequências do vírus, e a gravidade da situação e a proteção social aos mais pobres é extremamente residual e descontínua.

Enquanto a pandemia segue seu curso de mortes, principalmente nas periferias das cidades, atingindo os grupos sociais mais vulneráveis, entre eles indígenas, população de rua e moradores das periferias das cidades, as classes dominantes e seus representantes no poder executivo e legislativo implementam o que Mustafa (2019) denominou neoliberalismo radicalizado: aprovam leis que destroem direitos sociais e trabalhistas de povos tradicionais e quilombolas, dos trabalhadores, dos negros. E, ainda, completam esse trágico quadro destruindo e privatizando os recursos naturais e minerais do País.

Uma avalanche sem fim de leis e decretos que provocam o que o professor Ricardo Antunes chamou de devastação dos direitos sociais e trabalhistas. Para ilustrar essa avalanche destrutiva dos direitos sociais que, aliás, já estava em curso desde 2016, mas que nesse período passa a ser justificada em nome da crise sanitária, podemos mencionar a reforma 
trabalhista que retira diversos direitos dos trabalhadores (Dias, 2020) e, ainda em período de pandemia, a validação das negociações individuais entre patrões e empregados sem a presença do sindicato para a redução das jornadas e dos salários.

Do ponto de vista ambiental, a situação é de extrema gravidade: o desmatamento da Amazônia e a invasão dos garimpos colocam em risco as populações indígenas, especialmente em período de pandemia. Diversas medidas provisórias foram publicadas pelo governo Bolsonaro, com destaque para a Medida Provisória no 910, conhecida com PL da grilagem, o PL n²633/2020 que permite a regularização de terras públicas ocupadas ilegalmente; e ainda, em 2019 foram liberados 475 agrotóxicos e em 2020, no momento da pandemia, mais 118 agrotóxicos (Grigori, 2020).

Por outro lado, segue valendo o que já mencionava Evaldo Vieira (1992) nos anos 1990: o Estado é mínimo para os trabalhadores e máximo para o capital. Enquanto os direitos dos trabalhadores são reduzidos, o socorro às grandes empresas segue em curso pela via do BNDS que destinou bilhões de reais para socorrer as empresas do setor aéreo e outras consideradas como estratégicas (Mendes, 2020).

A área da educação, especialmente o ensino superior passa por um processo de mercantilização, iniciado nos anos 1980, mas que se aprofunda a partir dos anos 1990. Grandes conglomerados educacionais passam o compor o quadro de instituições de ensino e o Estado reordena suas funções na área atuando como regulador do bem público e, portanto, compartilhando com o setor privado as verbas destinadas à educação. A Lei de Diretrizes e Bases da Educação (LDB n 9.394/96) viabiliza este processo e, durante os anos dos governos do Partido dos Trabalhadores (2003 a 2016) verifica-se a implementação em sintonia com as orientações os organismos internacionais. Com isso, a mercantilização do ensino superior no âmbito da graduação e pós-graduação lato sensu avança de maneira avassaladora, especialmente na modalidade do ensino a distância. Nesse período, apesar do aumento das universidades públicas e dos institutos federais no País, a maioria das vagas disponibilizadas vão diretamente ou indiretamente para o setor privado (Pereira, 2009). 
A partir do golpe jurídico-parlamentar de 2016, a educação brasileira vem passando por um processo profundo de retrocesso em um contexto nacional marcado pela ascensão do conservadorismo e aprofundamento da privatização do ensino.

No governo do presidente Jair M. Bolsonaro agrava-se o ataque ao ensino superior, em particular às áreas de ciências humanas e sociais, cortes de bolsas e financiamentos de pesquisa, tentativas de intervenções nas universidades públicas, tentativa de retirada das cotas para negros e indígenas. Esse quadro encontra rebatimentos no Serviço Social, com graves ameaças de extinção de programas.

Como parte da organização da área de serviço social, no Seminário Meio Termo da Área 32 de Serviço Social da Capes, ocorrido em novembro/2019, nasceu a estratégia de publicação de uma edição especial da Revista Serviço Social \& Sociedade sobre a produção dos Programas de Pós-Graduação para fortalecer os programas com nota 3 na Capes e destacar suas produções e inserções sociais.

Essa proposta foi muito bem acolhida pelos gestores da Cortez Editora que há mais de 40 anos têm apoiado efetivamente as produções de conhecimento crítico na área de Serviço Social. Neste cenário de obscurantismo que vem enfrentando a educação, a ciência e o conhecimento, apoiar e alavancar as produções dos Programas de Pós-Graduação trata-se de uma questão política de resistência às propostas governamentais de fusão de Programas nota 3 e/ou redução da área de humanidades, como está sendo cogitado na política de desmonte da Pós-Graduação da Capes, do CNPq e do Ministério de Ciência, Tecnologia e Inovações.

Assim, reforça-se a importância do eixo temático deste número da Revista centrado na produção sobre a inserção social desenvolvida pelos Programas de Pós-graduação da área de Serviço Social. Na autoavaliação dos Programas, observa-se que a inserção social é um dos pontos comuns e ricos entre os Programas que são legitimados pela sociedade, configura-se como uma das ações de maior reconhecimento público e social. 
Esta edição especial contempla 13 artigos, sendo 12 dos Programas de Pós-Graduação e mais um da coordenação da área na CAPES. 0 artigo da coordenação da área tece uma contextualização dos Programas de Pós, os desafios e a inserção desses Programas na sociedade.

Os artigos dos Programas abordam a inserção social dos Programas de Pós-graduação em Serviço Social (nota 3), refletindo a particularidade de cada Programa na região onde se situa, demonstrando a importância da função social/política nos municípios, nos territórios e os impactos de suas ações para desenvolvimento social, local, regional, nacional na sociedade. A inserção social configura-se como uma estratégia de resistência na busca da equidade.

É importante destacar que o quesito inserção social foi introduzido na Ficha de Avaliação da Capes em 2007, como uma dimensão própria, constitutiva da Pós-Graduação. O objetivo era o de conhecer como e quanto a formação e a pesquisa poderiam impactar a sociedade, face aos desafios de necessárias transformações em nosso país.

O professor Dr. Renato Janine Ribeiro, quando diretor de Avaliação da Capes (2004-2008), em artigo sobre a Inserção Social (2007), afirmava a importância dessa inovação que significou o reconhecimento oficial pela Capes quanto à responsabilidade social da Pós-Graduação, em todas as suas áreas, não apenas com vistas a melhorar a ciência, mas também em melhorar o país. E exemplificava os impactos possíveis a serem alcançados: tecnológico, econômico, educacional, social, cultural, dentre outros. Argumentava o professor Janine Ribeiro: "com a introdução do quesito inserção social, damos um passo adiante: queremos também ver como esses mestres e doutores, bem como a pesquisa deles e de seus orientadores, atua em termos de desafios decisivos para a sociedade".

Desde então esse se tornou um quesito de grande importância e assim permanece no novo modelo de Avaliação da Capes para 2021. Guardada a autonomia das áreas, cada uma delas deve explicitar seu entendimento sobre a inserção social e os impactos decorrentes na sociedade.

Um alerta importante que consta no referido artigo do professor Janine Ribeiro diz respeito à compreensão da extensão na PG: 
Numa universidade de ponta, é frequente a extensão ser "a prima pobre" dentre as principais atividades da instituição. Compreende-se. $O$ segredo de uma boa instituição de ensino superior está na pós-graduação. É ela que, articulando a pesquisa com a formação de alunos já graduados, assegura a qualidade do ensino superior - e que faz que ele não seja, apenas ensino. Não há dúvida de que a extensão é importante, mas muitas vezes ela é pulverizada. Não é isso o que interessa no novo quesito, embora tenhamos o maior respeito pelas atividades de extensão. $O$ que se está valorizando é uma extensão de impacto, planejada, eficaz na consecução de objetivos que transformem a sociedade. (Brasil, 2007, p. 2).

Esta é uma questão a ser considerada, uma vez que a extensão, por vezes, é compreendida no âmbito de Programas de Pós-Graduação como a dimensão quase que constitutiva exclusivamente da inserção social. E, nesse sentido, os projetos de extensão devem ser qualificados de modo a efetivamente inserirem-se e criarem impactos nas diferentes dimensões da vida em sociedade e, com isso, responder às demandas postas, tendo em vista as inúmeras desigualdades sociais, econômicas, culturais, dentre outras, num país que ostenta a triste posição de ser um dos mais desiguais do mundo contemporâneo.

A inserção social da pós-graduação está, assim, relacionada necessariamente à formação de pessoas qualificadas para atender às demandas da sociedade, portanto, para contribuir no desenvolvimento científico e social, em âmbito público e privado, inserindo-se nas diversas dimensões da vida social sob processos de interação com setores e organismos socioprofissionais e científicos indispensáveis à contemporaneidade do debate e da resolução de questões prementes.

O documento da área de Serviço Social ${ }^{1}$, apresenta as perspetivas de inserção social e o do impacto social e econômico dos Programas de Pós-Graduação, destacando, por exemplo, a formação de recursos huma-

1 Documento da Área 32: Serviço Social - 2019. Coordenadora da área: Denise Bomtempo Birche de Carvalho. Coordenadora Adjunta de programas acadêmicos: Joana Valente Santana. Coordenadora de programas profissionais: Inez Terezinha Stampa. Disponível em: www.capes.br 
nos na área do ensino superior, para a atuação em políticas públicas, em serviços e na gestão pública, com destaque a assessorias e consultorias para formulação, gestão, implantação, análise e avaliação de políticas públicas e, na área do ensino, formação profissional em nível nacional e internacional; a atuação junto aos movimentos sociais, dentre outros.

Esses diferentes pontos de reflexão pressupõem um processo de participação efetiva da pós-graduação em diferentes níveis de inserção social, tendo como pressuposto, a formação de pessoas sob práticas de pesquisa aplicada, na medida em que o Serviço Social demanda o exercício de uma atuação profissional cuja realidade exige abertura a compreensão de novas determinações sociais a serem enfrentadas.

Nesse espaço, os desafios epistemológicos levam a perspectiva de inovações teórico-metodológicas no ensino, na pesquisa e na intervenção profissional em diálogo aberto e franco com outras disciplinas científicas e em nossa área de conhecimento.

Por fim, o conjunto de artigos expressos neste número da Revista revela a riqueza da inserção social dos Programas de Pós-Graduação nota 3 e o esforço de resistência e proposição num contexto marcado pelo contingenciamento, intensificação da mercantilização e privatização e pela desqualificação e criminalização das ciências humanas. O desafio está justamente nessa resistência e persistência na formação para a pesquisa em serviço social.

\section{Referências}

AMPARO, T. Por que a COVID-19 é tão letal entre negros? Disponível em: https://www. geledes.org.br/por-que-a-covid-19-e-tao-letal-entre-os-negros/. Acesso em: 2 jul. 2020.

DIAS, J.C.; CARMO, C.L.M. MP 955/220 e as principais alterações pela revogação da MP 905/2019. Disponível em: https:/www.migalhas.com.br/depeso/326189/mp-955-2020-e-as-principais-alteracoes-pela-revogacao-da-mp-905-2019. Acesso em: 2 jul. 2020.

GRIGORI, P. Em meio a pandemia, o governo Bolsonaro aprova 118 agrotóxicos em 2 meses. Repórter Brasil. Disponível em: https://apublica.org/2020/05/em-meio-a-pandemia-governo-bolsonaro-aprova-96-agrotoxicos-em-dois-meses/. Acesso em: 2 jul. 2020. 
MENDES, F. Os Planos do BNDES para resgatar empresas prejudicadas pela crise. Disponível em: https://veja.abril.com.br/economia/os-planos-do-bndes-para-resgatar-grandes-setores/. Acesso em: 2 jul. 2020.

MUSTAFA, P.S. Estado Capitalista brasileiro: análise dos direitos sociais em tempos de ortodoxia neoliberal. Katálysis, v.22, n 1, jan./abr. 2019. Florianópolis. https://www.scielo. br/scielo.php?script=sci_arttext\&pid=S1414-49802019000100100. Acesso em: 3 jul. 2020.

NICOLAV, V. O que passou na boiada de Ricardo Salles durante a pandemia ? https:// www.brasildefato.com.br/2020/06/09/o-que-passou-na-boiada-de-ricardo-salles-durante-a-pandemia Acesso em 02 de julho de 2020

NOGUERIA, L. COVID 19: Brasil tem 1252 novas mortes em 24 horas; total de óbitos ultrapassa $61 \mathrm{mil}$. a02https://olhardigital.com.br/coronavirus/noticia/covid-19-brasil-tem-1-252-novas-mortes-em-24h-total-de-obitos-ultrapassa-61-mil/98089. Acesso em: 2 jul. 2020.

PEREIRA, L.D. Mercantilização do ensino superior, educação a distância e serviço social. Katálysis, v.12, n. 2, jul/dez.2009. Florianópolis. https://www.scielo.br/scielo.php?scrip$\mathrm{t}=$ sci_arttext\&pid=S1414-49802009000200017\&lng=pt\&tlng=pt. Acesso em: 3 jul. 2020.

RIBEIRO, R. J. Inserção Social www.capes.org.br storis, artigos 23_8_07 PDF p. 2

RIBEIRO, R. J. CAPES. Inserção social. Disponível em: https:/www.capes.gov.br/images/ stories/download/artigos/Artigo_23_08_07.pdf. Acesso em: 10 jan. 2020.

VIEIRA, E. Democracia e Política Social. São Paulo: Cortez. 1992.

\section{Sobre as autoras}

Mariangela Belfiore Wanderley - Assistente social, professora associada do Departamento de Serviço Social. Docente do Programa de Pós-Graduação em Serviço Social.

E-mail: mariangela.belfiore@gmail.com

Maria Liduína de Oliveira e Silva - Docente do curso de Serviço Social e do Programa de Pós-Graduação em Serviço Social e Políticas Sociais.

E-mail: liduoliveira90@gmail.com

Raquel Santos Sant'Ana - Doutora em Serviço Social. Professora livre docente da Faculdade de Ciências Humanas e Sociais de Franca.

E-mail: raquelssfranca@yahoo.com.br

Rosangela Dias O. DA Paz - Assistente social, doutora em Serviço Social. E-mail: rosapaz@uol.com.br. 